\title{
Profil Klinis dan Etiologi Pasien Keterlambatan Perkembangan Global di Rumah Sakit Gipto Mangunkusumo Jakarta
}

\author{
I Gusti Ngurah Suwarba, * Dwi Putro Widodo, ** RA Setyo Handryastuti** \\ *Departemen Ilmu Kesehatan Anak, Fakultas Kedokteran Universitas Udayana-Rumah Sakit Sanglah \\ Denpasar \\ ** Departemen Ilmu Kesehatan Anak, Fakultas Kedokteran Universitas Indonesia - Rumah Sakit Cipto \\ Mangunkusumo, Jakarta
}

\begin{abstract}
Latar belakang. Perkembangan anak meliputi aspek motorik halus, motorik kasar, bahasa/berbicara, personal sosial, kognitif, dan aktivitas sehari-hari. Keterlambatan perkembangan global (KPG) adalah keterlambatan bermakna pada lebih dari dua domain perkembangan. Etiologi sangat bervariasi, angka kejadian sekitar 1\%-3\% anak-anak di seluruh dunia, sedangkan di Indonesia sampai saat ini belum pernah dilaporkan.

Tujuan. Mengetahui prevalensi, karakteristik, etiologi, dan faktor-faktor yang berhubungan dengan etiologi KPG di RS Dr. Cipto Mangunkusumo Jakarta.

Metode. Penelitian retrospektif dilakukan pada 151 anak KPG di Poliklinik Neurologi anak RS Dr. Cipto Mangunkusumo Jakarta pada Januari 2006-Juli 2008. Kriteria inklusi anak didiagnosis KPG, berumur $<5$ tahun. Hasil. Prevalensi KPG di Poliklinik Neurologi Anak RS Dr. Cipto Mangunkusumo Jakarta pada Januari 2006-Juli 2008 didapatkan pada 151(2,3\%) dari 6487 kunjungan. Keluhan terbanyak, belum bisa berjalan dan berbicara $71(47,1 \%)$ kasus, $84(55,6 \%)$ laki-laki, dan rerata umur $(21,8 \pm 13,1)$ bulan. Riwayat kelahiran 33(21,9\%) kurang bulan, 45(29,8\%) BBLR, 125(79,2\%) lahir pervaginam, 46(30,\%) tidak segera menangis. Gangguan perkembangan dalam keluarga ditemukan pada $20(13,2 \%)$ kasus. Karakteristik klinis $81(53,6 \%)$ mikrosefali, $67(44,4 \%)$ kasus gizi kurang dan gizi buruk. Gambaran dismorfik 19 (12,6\%) kasus, riwayat kejang 57(37,7\%) kasus. Etiologi dapat diidentifikasi pada 97(64,2\%) kasus. Lima etiologi terbanyak 33(21,9\%) disgenesis cerebral, 18(11,9\%) palsi cerebral, 15(9,9\%) infeksi TORCH, 11(7,3\%) sindrom genetik, dan 7(4,6\%) kelainan metabolik kongenital. Analisis bivariat, ditemukan perbedaaan bermakna pada riwayat kejang, jenis kelamin, mikrosefali, dan gambaran dismorfik antara etiologi yang diketahui dan etiologi tidak diketahui dengan $p=0,025 ; 0,016$; 0,$018 ;<0,0001$. Analisis multivariat, ada hubungan bermakna antara keberhasilan identifikasi etiologi dengan jenis kelamin, mikrosefali, dan gambaran dismorfik dengan $p=0,003 ;<0,0001$ dan 0,006 .

Kesimpulan. Prevalensi keterlambatan perkembangan global di poliklinik anak RS Dr. Cipto Mangunkusumo Jakarta 2,3\%. Karakterisitik klinis yang berhubungan bermakna dengan keberhasilan identifikasi etiologi adalah jenis kelamin laki-laki, mikrosefali, dan adanya gambaran dismorpik. (Sari Pediatri 2008;10(4):255-61).
\end{abstract}

Kata kunci: KPG, mikrosefali-dismorfik, disgenesis cerebral

\footnotetext{
Alamat Korespondensi:

Dr. I Gusti Ngurah Made Suwarba, SpA. SMF IKA FK UNUD/RSUP

Sanglah. Jl. P. Nias Denpasar Telp. 620361-227911-15. 80114
} 
$\mathrm{P}$ eriode terpenting pertumbuhan dan perkembangan anak adalah umur di bawah 5 tahun. ${ }^{1,2}$, Beberapa domain perkembangan tersebut antara lain motorik halus, motorik kasar, bahasa/berbicara, personal sosial/interaksi sosial, kognitif, dan aktivitas sehari-hari. Global developmental delay (GDD) atau keterlambatan perkembangan global (KPG), merupakan suatu keadaan ditemukannya keterlambatan yang bermakna lebih atau sama dengan 2 domain perkembangan tersebut. ${ }^{3}$ Keterlambatan bermakna artinya pencapaian kemampuuan pasien kurang dari 2 standar deviasi (SD) dibandingkan dengan rata-rata populasi pada umur yang sesuai. Istilah KPG dipakai untuk anak umur kurang dari 5 tahun. Pada anak berumur lebih dari 5 tahun saat tes IQ sudah dapat dilakukan dengan hasil yang akurat, istilah yang dipakai adalah retardasi mental. ${ }^{3,5}$ Angka kejadian keterlambatan perkembangan secara umum sekitar 10\% anak-anak di seluruh dunia. Sedangkan angka kejadian KPG diperkirakan 1\%-3\% anak-anak berumur $<5$ tahun. Etiologi KPG dapat dibedakan menjadi kejadian prenatal, perinatal, pasca natal, dan idiopatik.

Di Indonesia, suatu penelitan di seratus sepuluh wilayah Puskesmas di Pulau Jawa tahun 1987 mendapatkan 13\% balita berpotensi mengalami keterlambatan perkembangan. Penelitian di daerah kumuh perkotaan di Bandung tahun 1998, ditemukan 28,5\% balita mengalami keterlambatan perkembangan.6,7 Sedangkan berapa angka kejadian KPG di Indonesia sampai saat ini belum pernah dilaporkan. Tujuan penelitian untuk mengetahui prevalensi, karakteristik, etiologi serta faktor-faktor yang berhubungan dengan identifikasi etiologi KPG di rumah sakit Cipto Mangunkusumo Jakarta.

\section{Metode}

Penelitian dilakukan secara retrospektif, deskriptif analitik. Data diambil dari catatan medik pasien rawat jalan di Poliklinik Neurologi Anak Departemen IKA FKUI-RSCM Jakarta antara Januari 2006-31 Juli 2008. Semua pasien yang didiagnosis global developmental delays dan developmental delay dicatat nama dan nomor rekam medis. Hanya rekam medis yang lengkap dipergunakan sebagai subjek penelitian. Pada pasien developmental delay dilakukan klarifikasi terhadap domain keterlambatan untuk menentukan keterlambatan perkembangan global. Kriteria inklusi semua anak yang didiagnosis KPG dan berumur kurang dari 5 tahun pada saat pertama kali didiagnosis. Kriteria eksklusi adalah KPG yang disebabkan oleh autisme, PPD-NOS, ADHD, hidrosefalus, meningoencephalokel, dan mielomeningokel. Semua data pasien dicatat dalam kuesioner penelitian yang meliputi data demografi, data klinis, serta hasil pemeriksaan penunjang seperti USG, CT Scan, MRI kepala, pemeriksaan metabolik dan sitogenetika, kemudian ditentukan etiologinya. Data ditabulasi dan dianalisis bivariat dengan uji kaikuadrat atau uji Fischer. Untuk mengetahui berbagai faktor klinis yang berhubungan dengan identifikasi etiologi, dilakukan analisis multivariat dengan analisis regresi logistik. Kuatnya hubungan antara variabel independen dengan variabel dependen dinyatakan dengan rasio odds dengan tingkat kemaknaan $\mathrm{p}<0,05$ dan interval kepercayaan 95\%. Analisis menggunakan program komputer, hasil disajikan dalam bentuk narasi dan tabel.

\section{Hasil}

Didapatkan 267 pasien yang didiagnosis keterlambatan perkembangan (developmental delays) dan setelah dilakukan klarifikasi terhadap domain keterlambatan perkembangan, maka didapatkan 151 kasus KPG. Pada 116 pasien mengalami satu domain keterlambatan perkembangan yakni 47 keterlambatan motor dan 34 keterlambatan bicara. Terdapat 35 pasien tidak diikutsertakan karena 12 pasien autism/PPD-NOS, 9 hidrocephalus, meningoensefalokel atau mielomeningokel, dan 14 data tidak lengkap. Jumlah kunjungan pasien selama periode penelitian di poliklinik anak RS Dr. Cipto Mangunkusumo Jakarta 6487 pasien, sehingga prevalensi pasien keterlambatan perkembangan global adalah 2,3\%.

Rerata umur pasien pada saat pertama kali datang dan didiagnosis KPG adalah $(21,8 \pm 13,1)$ bulan, dengan rentang umur 3-56 bulan. Keluhan utama terbanyak adalah belum bisa berjalan dan berbicara $71(47,1 \%)$ kasus. Laki-laki lebih banyak dari perempuan dengan rasio 1,3:1. Karakteristik demografi pasien meliputi umur, jenis kelamin, umur kehamilan, berat badan lahir, cara persalinan, keadaan saat lahir dan riwayat keluarga tertera pada Tabel 1 . 
Karakteristik klinis seperti lingkar kepala, status gizi, riwayat kejang, gambaran dismorfik, jumlah domain keterlambatan perkembangan, identifiaksi etiologi dan tipe gangguan neurologis tertera pada Tabel 2

Didapatkan 97(64,2\%) pasien dapat didentifikasi etiologinya. Gambaran etiologi secara rinci tertera pada Tabel 3. Lima penyebab terbanyak adalah disgenesis sereberal, palsi sereberal, infeksi TORCH, sindrom genetik, dan kelainan metabolik kongenital. Berdasarkan waktu terjadinya kelainan maka faktor prenatal dan perinatal sebanyak 77 (79,4\%), sedangkan pasca natal $20(20,6 \%)$ pasien.

Berdasarkan analisis bivariat, didapatkan perbedaaan yang bermakna pada riwayat kejang, jenis kelamin, mikrosefali, dan gambaran dismorfik antara etiologi yang diketahui dan etiologi tidak diketahui

Tabel 1. Karakteristik demografi pasien keterlambatan perkembangan global.

\begin{tabular}{lcc}
\hline Karakteristik & $\begin{array}{c}\text { Jumlah KPG } \\
\mathrm{n}=151\end{array}$ & Presentase (\%) \\
\hline Jenis kelamin & & \\
$\quad$ Laki-laki & 84 & 55,6 \\
$\quad$ Perempuan & 67 & 44,4 \\
Umur (bulan) & & \\
$0-<6$ & 5 & 3,3 \\
$6-<12$ & 27 & 17,9 \\
$12-<18$ & 19 & 12,6 \\
$18-<24$ & 20 & 13,2 \\
$24-<36$ & 55 & 36,4 \\
$36-60$ & 25 & 16,6 \\
Umur kehamilan & & \\
$\quad$ Preterm & 33 & 21,9 \\
Aterm & 118 & 78,1 \\
Berat badan lahir (gram) & & \\
$\quad<1500$ & 1 & 0,7 \\
1500 - <2500 & 44 & 29,1 \\
2500 - 4000 & 101 & 66,9 \\
$\quad>4000$ & 5 & 3,3 \\
Cara persalinan & & \\
Spontan & 119 & 78,8 \\
$\quad$ Sectio caesaria & 26 & 17,2 \\
$\quad$ Lain-lain & 6 & 4,0 \\
Keadaan saat lahir & & \\
$\quad$ Segera menangis & 105 & 69,5 \\
$\quad$ Tak segera menangis & 46 & 30,5 \\
Riwayat keluarga & & \\
Ada & 20 & 13,2 \\
$\quad$ Tidak ada & 131 & 86,8 \\
\hline
\end{tabular}

dengan nilai $p=0,025 ; 0,016 ; 0,018$; dan $<0,0001$. Analisis multivariat menunjukkan ada hubungan yang bermakna antara keberhasilan identifikasi etiologi dengan jenis kelamin, mikrosefali dan gambaran dismorfik dengan nilai $p=0,003 ;<0,0001$ dan 0,006 tertera pada Tabel 5 .

\section{Pembahasan}

Keluhan utama terbanyak orang tua membawa anaknya berobat adalah "belum bisa berjalan dan

Tabel 2. Karakteristik klinis pasien keterlambatan perkembangan global

\begin{tabular}{|c|c|c|}
\hline Karakteristik & $\begin{array}{c}\text { Jumlah KPG } \\
\mathrm{n}=151\end{array}$ & $\begin{array}{c}\text { Prosentase } \\
\quad(\%)\end{array}$ \\
\hline \multicolumn{3}{|l|}{ Keluhan utama } \\
\hline Belum bisa tegak kepala & 28 & 18,5 \\
\hline Belum bisa duduk & 28 & 18,5 \\
\hline Belum bisa berdiri & 10 & 6,6 \\
\hline Belum bisa berjalan dan berbicara & 71 & 47,1 \\
\hline Kejang & 14 & 9,3 \\
\hline \multicolumn{3}{|l|}{ Lingkar kepala } \\
\hline Mikrosefali & 81 & 53,6 \\
\hline Normosefali & 66 & 43,7 \\
\hline Makrosefali & 4 & 2,6 \\
\hline \multicolumn{3}{|l|}{ Status gizi } \\
\hline Gizi lebih & 4 & 2,6 \\
\hline Gizi baik & 80 & 53,0 \\
\hline Gizi kurang & 59 & 39,1 \\
\hline Gizi buruk & 8 & 5,3 \\
\hline \multicolumn{3}{|l|}{ Gambaran dismorpik } \\
\hline Ada & 19 & 12,6 \\
\hline Tidak ada & 132 & 87,4 \\
\hline \multicolumn{3}{|l|}{ Riwayat kejang } \\
\hline Ada & 57 & 37,7 \\
\hline Tak ada & 94 & 62,3 \\
\hline \multicolumn{3}{|l|}{ Domain terlambat } \\
\hline 2 & 35 & 23,2 \\
\hline$>2$ & 116 & 76,8 \\
\hline \multicolumn{3}{|l|}{ Tipe gangguan neurologis } \\
\hline Sentral & 103 & 68,2 \\
\hline Perifer & 15 & 9,9 \\
\hline Campuran & 13 & 8,6 \\
\hline Sulit ditentukan & 20 & 13,2 \\
\hline \multicolumn{3}{|l|}{ Identifikasi etiologi } \\
\hline Tahu & 97 & 64,2 \\
\hline Tidak tahu & 54 & 35,8 \\
\hline
\end{tabular}


Tabel 3. Identifikasi etiologi keterlambatan perkembangan global

\begin{tabular}{lcc}
\hline Etiologi & Jumlah & Prosentase (\%) \\
\hline $\begin{array}{l}\text { Cereberal disgenesis: disgenesis cc (4), disgenesis pons (1), } \\
\quad \text { disgenesis serebri(1), leukomalasia (5), leukodistrofi(4), }\end{array}$ & 33 & 21,9 \\
$\quad$ holopronsefali(2), hidransefali (3), kista arahnoid (2), & & \\
$\quad$ kista porensefali(4), meningoensefalokel(1), & & \\
$\quad$ skinsefali(2), serebral atrofi difus (3) & 18 & 11,9 \\
Palsi serebral & 15 & 9,9 \\
Infeksi TORCH & 11 & 7,3 \\
Sindrom genetik: Down's syndrome (5), Dandy Walker syndrome (2), & & 4,6 \\
$\quad$ neurofibromatosis (3), tuberosklerosis (1) & 7 & 3,3 \\
Kelainan metabolik kongenital: hipotiroid kongenital & 5 & 2,0 \\
Kelainan neuromuskular & 3 & 2,0 \\
Hipotoni kongenital & 3 & 1,3 \\
HIE & 2 & 35,8 \\
Malnutrisi & 54 & 100 \\
\hline Tidak diketahui & 151 & \\
\hline Jumlah & & \\
\hline
\end{tabular}

Tabel 4. Hubungan antara klinis dan etiologi keterlambatan perkembangan global

\begin{tabular}{|c|c|c|c|c|c|}
\hline \multirow{2}{*}{ Variabel } & \multicolumn{2}{|c|}{ Etiologi KPG } & \multirow{2}{*}{ OR } & \multirow{2}{*}{$p$} & \multirow{2}{*}{ IK 95\% } \\
\hline & Tahu & Tidak tahu & & & \\
\hline \multicolumn{6}{|l|}{ Riwayat keluarga } \\
\hline Ada & 14 & 6 & 1,349 & 0,564 & 0,$486 ; 3,743$ \\
\hline Tidak ada & 83 & 48 & & & \\
\hline \multicolumn{6}{|l|}{ Riwayat kejang } \\
\hline Ada & 43 & 14 & 2,275 & 0,025 & $1,098: 4,715$ \\
\hline Tidak ada & 54 & 40 & & & \\
\hline \multicolumn{6}{|l|}{ Umur kehamilan } \\
\hline Kurang bulan & 21 & 12 & 0,967 & 0,935 & 0,$435 ; 2,159$ \\
\hline Cukup bulan & 76 & 42 & & & \\
\hline \multicolumn{6}{|l|}{ BBLR } \\
\hline Ada & 32 & 12 & 1,723 & 0,163 & 0,$799 ; 3,716$ \\
\hline Tidak ada & 65 & 42 & & & \\
\hline \multicolumn{6}{|l|}{ Keadaan saat lahir } \\
\hline Segera menangis & 66 & 39 & 0,819 & 0,593 & 0,$394 ; 1,704$ \\
\hline Tidak segera menangis & 31 & 15 & & & \\
\hline \multicolumn{6}{|l|}{ Jenis kelamin } \\
\hline Laki-laki & 61 & 23 & 2,284 & 0,016 & 1,$159 ; 4,502$ \\
\hline Perempuan & 36 & 31 & & & \\
\hline \multicolumn{6}{|l|}{ Mikrosefali } \\
\hline Ada & 59 & 22 & 2,258 & 0,018 & 1,$145 ; 4,453$ \\
\hline Tidak ada & 38 & 32 & & & \\
\hline \multicolumn{6}{|l|}{ Gambaran dismorfik } \\
\hline Ada & 18 & 1 & 1,692 & 0,000 & $468 ; 1,950$ \\
\hline Tidak ada & 79 & 53 & & & \\
\hline
\end{tabular}


I Gusti Ngurah Suwarba dkk: Profil Klinis dan Etiologi Pasien Keterlambatan Perkembangan Global di RSCM, Jakarta

Tabel 5. Analisis multivariat regresi logistik untuk keberhasilan identifikasi etiologi anak dengan keterlambatan perkembangan global.

\begin{tabular}{lllll}
\hline Variabel Independen & $\beta$ & SE & $p$ & IK 95\% \\
\hline Jenis kelamin & 0,220 & 0,072 & 0,003 & 0,$077 ; 0,363$ \\
Dismorfik & 0,425 & 0,108 & 0,000 & 0,$212 ; 0,638$ \\
Mikrosefali & 0,202 & 0,072 & 0,006 & 0,$060 ; 0,345$ \\
\hline
\end{tabular}

berbicara”. Hal ini sesuai dengan rata-rata umur pertama kali didiagnose KPG yaitu lebih kurang 21,8 bulan, berarti kebanyakan orang tua terlambat mengetahui keterlambatan perkembangan pada anaknya sehingga penanganannya juga terlambat. Keterlambatan perkembangan harus dideteksi secara dini dan stimulasi sedini mungkin untuk mendapatkan hasil yang optimal.11,13,17,23 Kenapa respon orang tua terlambat, belum diketahui secara pasti dan memerlukan penelitian lebih lanjut. Hasil yang sama juga ditemukan pada penelitian Shevell dkk.10

Pada penelitian kami etiologi keterlambatan perkembangan global dapat diidentifikasi $64,2 \%$ dari 151 subjek, sedikit lebih banyak dibandingkan penelitian Sour dkk ${ }^{10}$ di rumah sakit Montreal Kanada yang menemukan etiologi 55\% dari 261 subjek yang diteliti. Hal ini terjadi oleh karena pada penelitian kami, etiologi palsi serebral dimasukkan dalam analisis sedangkan pada penelitian Sour dkk, palsi serebral dieksklusi. Penelitian retrospektif serupa di Turki, dapat mengidentifikasi etiologi 63\% dari 247 kasus KPG. ${ }^{14}$ Beberapa perbedaan yang ada, dapat disebabkan oleh perbedaan metodologi, cara pemilihan sampel, dan pemeriksaan penunjang yang dapat dikerjakan di rumah sakit setempat. ${ }^{2,12,15}$

Etiologi diketahui pada lebih dari $50 \%$ kasus, sehingga dapat memberikan manfaat antara lain memberikan tata laksana yang sesuai etiologinya, memberikan penjelasan tentang kemungkinan berulangnya kasus yang sama di dalam keluarga, membuat prognosis yang lebih akurat dan kemungkinan memberikan intervensi spesifik kepada pasien. ${ }^{8,10}$ Etiologi KPG yang dapat diidentifikasi paling banyak adalah disgenesis serebral. Oleh karena itu, dianjurkan pada pasien KPG yang tidak dapat diidentifikasi etiologinya dari anamnesis dan pemeriksaan fisik, sebaiknya dilakukan pemeriksaan CT Scan atau MRI secara rutin. ${ }^{11}$ Kami juga menemukan 25,8\% pasien KPG tidak diketahui etiologinya, sebagian di antaranya dicurigai suatu sindrom genetik, tetapi pemeriksaan sitogenetik tidak dapat dilakukan oleh karena suatu kendala biaya atau sebab lain. Pemeriksaan sitogenetika juga dianjurkan secara rutin pada pasien yang etiologinya tidak dapat diidentifikasi dari anamnesis dan pemeriksaan fisik. ${ }^{2,24}$ Kelompok etiologi seperti palsi sereberal, infeksi TORCH, hipoksik iskemik ensefalopati dan malnutrisi sebenarnya adalah etiologi yang dapat dicegah. ${ }^{18,19,20}$ Kelompok etiologi ini meliputi sekitar 39,2\% subjek. Hal ini bisa dijadikan masukan kepada para pembuat keputusan sehingga dapat membuat strategi pencegahan untuk mengurangi munculnya kasus yang sama pada masa mendatang.

Pasien KPG laki-laki lebih banyak dibandingkan perempuan yang dapat diidentifikasi etiologinya (63\% berbanding 37\%). Pada beberapa penelitian sebelumnya, anak laki-laki lebih banyak menderita KPG, pada penelitian kami 55,6\% pasien laki-laki. Penemuan yang sama pada penelitian Sour dkk, $74 \%$ pasien KPG laki-laki, dan etiologi yang dapat diidentifikasi 59\% pada anak laki-laki dan 30\% perempuan. ${ }^{10}$ Namun bagaimana hal ini dapat terjadi sampai saat ini belum dapat dijelaskan, diperkirakan karena kondisi faktor $x$-linked atau $x$-limited. Telah diketahui beberapa kondisi $x$-linked yang dapat menyebabkan gangguan perkembangan, terutama sindrom Fragile x, sindrom Coffin-Lowry, defek creatine transporter, dan sindrom okuloserebrorenal.9,15,24

Status gizi kurang dan gizi buruk ditemukan pada $45 \%$ kasus, kemungkinan disebabkan adanya kesulitan makan pada pasien KPG karena adanya gangguan pada oromotor. Keadaan ini harus mendapat perhatian yang lebih baik pada upaya tata laksana pasien karena jika status gizi tidak diperbaiki maka semakin memperberat keadaan penyakitnya. Defisiensi nutrien tertentu sangat menentukan perkembangan susunan saraf pusat maupun perifer dan menimbulkan kelainan neurologis. ${ }^{26}$ Adanya gambaran dismorfik tidak konsisten ditemukan sebagai nilai prediktif untuk identifikasi etiologi KPG pada penelitian sebelumnya. Gambaran dismorfik pada umumnya berhubungan dengan abnormalitas genetika kongenital antara lain sindrom fragile- $x$, sindrom Cornelia de Lange, sindrom 
Prader-Willi, dan sindrom Angelman. ${ }^{9,10}$ Pada penelitian kami adanya gambaran dismorfik berhubungan dengan beberapa sindrom genetik seperti sindrom Down's, hipotiroid kongenital, sindrom Dandy Walker, dan neurofibromatosis.

Pada beberapa penelitian sebelumnya dilaporkan tidak ditemukan hubungan antara berat ringannya KPG dengan keberhasilan identifikasi etiologinya. Anak dengan KPG ringan dan berat sama peluangnya untuk dapat diidentifikasi etiologinya. Dengan demikian konsultasi kepada dokter saraf anak diperlukan tanpa memperhatikan berat ringannya KPG yang dialami oleh seorang anak. ${ }^{2,9,10}$ Pada penelitian kami berat ringannya KPG tidak dapat ditentukan karena data pemeriksaan klinis tidak cukup lengkap untuk keperluan tersebut. Gambaran mikrosefali, didapatkan berhubungan bermakna dengan keberhasilan mengidentifikasi etiologi. Hal ini dapat dipahami bahwa mikrosefali merupakan manifestasi beberapa kelainan yang terjadi di dalam otak seperti infeksi TORCH, disgenesis serebral atau anomali otak lainnya yang menganggu pertumbuhan dan maturasi otak. ${ }^{2,5,11,15}$

Ada beberapa kelemahan penelitian retrospektif. Pertama, pengambilan data kurang lengkap, sehingga akan menemukan hambatan dalam pengolahan data seperti menentukan derajat berat ringannya KPG tidak bisa dilakukan. Kedua, subjek penelitian hanya diambil dari Poliklinik Saraf Anak, sedangkan pasien yang masuk poliklinik swasta RSCM tidak diikutsertakan pada penelitian, jadi mungkin kurang representatif mewakili populasi Jakarta dan sekitarnya secara keseluruhan. Ketiga, cukup banyak pasien KPG yang dicurigai karena kelainan kromosom tetapi etiologi pasti tidak dapat ditentukan karena pemeriksaan sitogenetik tidak bisa dikerjakan karena beberapa alasan. Beberapa laporan sebelumnya menyebutkan bahwa pemeriksaan kromosom dapat mendeteksi kelainan pada 6,8\% pasien KPG sedang dan berat dan 1,1\% pada anak dengan KPG ringan. ${ }^{10,24}$ Jika pemeriksaan kromosom dapat dikerjakan maka kami dapat mengidentifikasi etiologi KPG lebih banyak.

\section{Kesimpulan}

Prevalensi keterlambatan perkembangan global di poliklinik anak RSCM Jakarta adalah 151(2,3\%). Keluhan utama terbanyak adalah "belum bisa berjalan dan berbicara”, dengan rerata umur $(21,8 \pm 13,1)$ bulan. Kebanyakan anak laki-laki, rasio laki-laki dan perempuan 1,25:1. Pada riwayat kelahiran didapatkan $21,9 \%$ kasus lahir kurang bulan, 29,8\% BBLR, 79,2\% lahir pervaginam, dan 30,\% tidak segera menangis. Gangguan perkembangan dalam keluarga ditemukan pada $13,2 \%$ kasus. Karakteristik klinis terbanyak $53,6 \%$ mikrosefali, $44,4 \%$ gizi kurang dan gizi buruk. Etiologi terbanyak adalah disgenesis cerebral, palsi cerebral, infeksi TORCH, sindrom genetik, dan kelainan metabolik kongenital. Analisis multivariat menunjukkan terdapat hubungan antara keberhasilan identifikasi etiologi dengan jenis kelamin, mikrosefali, dan gambaran dismorfik.

\section{Daftar Pustaka}

1. Menkes JH, Moser FG. Neurologic examination of the child and infant. Dalam: Menkes JH, Sarnat HB, penyunting. Child neurology. Philadelphia: Lippincott Williams \& Wilkins; 2006.h.1-27.

2. Shevell M, Ashwal S, Donley D, Flint J, Gingold M, Hirzt D, dkk. Practice parameter: Evaluation of the quality standards subcommittee of the American Academy of Neurology and the practice committee of the Child Neurology Society. Neurology 2003;60;367-80.

3. Tanuwijaya S. Kebutuhan dasar tumbuh kembang anak. Dalam: Narendra M, Sularyo S, Soetjiningsih, Suyitno H, Ranuh IGN, penyunting. Buku ajar tumbuh kembang anak dan remaja, edisi ke-1. Jakarta: Sagung Seto; 2002.h.13-21.

4. Sherr EH, Shevell MI. Mental retardation and global developmental delay. Dalam: Swaiman KF, Ashwal $S$, Ferriero DM, penyunting. Pediatric neurology, principles and practice. Edisi ke-4. Philadelphia: Mosby; 2006.h.799-20.

5. Soetomenggolo TS. Pemeriksaan neurologis pada anak dan bayi. Dalam: Soetomenggolo TS, Ismael S, penyunting. Buku ajar neurologi anak. Jakarta: Ikatan Dokter Anak; 1999.h.1-35.

6. Tim Peneliti Direktorat Bina Kesehatan Keluarga dan Direkorat Kesehatan Jiwa, Departemen Kesehatan Republik Indonesia. Laporan akhir penelitian pengembangan paket pemantauan perkembangan anak. Jakarta, 1990.

7. Eddy F, Anna A, Ilsa N, Muchlisah N, Selly, Yulia S. Pola keterlambatan perkembangan balita di daerah pedesaan dan perkotaan Bandung, serta faktor-faktor 
yang mempengaruhinya. Sari Pediatri 2003;4:168-75.

8. Needlman RD. Growth and development. Dalam: Behrman RE, Kliegman RM, Arvin AM, penyunting. Nelson's textbook of pediatrics. Edisi ke-16. Philadelphia: WB Saunders; 2000.h.23-65.

9. Shevell MI, Majnemer A, Rosenbaum P,Abrahamowicz A. Etiologic determination of childhood development delay. Brain dev 2001;23.4;228-35.

10. Srour M, Mazer B, Shevell MI. Analysis of clinical features predicting etiologic yield in the Assessment of global development delay. Pediatrics 2006;118;139-45.

11. McDonald L, Rennie A, Tolmie J, Galloway P, McWilliam R. Investigation of global developmental delay. Arch Dis Child.2006:91;701-5.

12. Shevell MI, Majnemer A, Rosenbaum P, Abrahamowicz. Profile of referral for early childhood developmental delay to ambulatory subspecialty clinics. J Child Neurol 2001;16;645-53.

13. Essex C, Roper H. Late diagnosis of duchenne's muscular dystrophy presenting as global developmental delay. $\mathrm{Br}$ Med J 2000;323:37-8.

14. Özmen M, Tatli B, Aydinli N, Çaliskan M, Demirkol M, Kayserili H. Etiologic evaluation in 247 children with global developmental delay at Istanbul, Turkey. J Trop Pediatr 2005;51:310-3.

15. Srour M, Mazer B, Shevell MI. Diagnosing Sotos syndrome in the setting of global developmental delay and macrocephaly. J Child Neurol 2006;21;287-90.

16. National Metabolic Biochemistry Network. Best practice guidelines for the biochemical investigation of global developmental delay for inherited metabolic disorder (IMD). Arch Dis Child 2005;90:1128-32.
17. Chen IC, Lee HC, Yeh GC, Lai CH, Chen SC. The relationship between parental concerns and professional assessment in developmental delay in infants and children-a hospital-base study. J Chin Med Assoc 2004;67;239-44.

18. Anggraini A, Abdulrahman S, Nelly AR, Meita D. Preterm and low birth weight as risk factor for infant delayed development. Pediatr Indones 2008;48:1-4.

19. Peryoga SU. The risk for delayed development in low birth weight, appropriate for gestational age preterm infant. Pediatr Indones 2005;45:154-9.

20. Bennett FC. Developmental outcome. Dalam: Avery GB, Fletcher M, MacDonald MG, penyunting. Neonatology: pathophysiology and management of newborn, edisi ke-5. Philadelphia: Lippincott; 1999.h.1479-97.

21. Shevell MI, Majnemer A, Platt RW, Webster R, Birnhaum R. Developmental and function outcome in children with global developmental delay or developmental language impairment. Developmental medicine and child neurology 2005:47:678-83.

22. First LR, Palfrey JS. The infant or young child with developmental delay. N Engl J Med 1994;330;478-83.

23. Kurtz LA, Scull SA. Rehabilitation for developmental disabilities. Pediatr Clin N Am 1993;40:629-43.

24. Shaffer LG. Guideline on the cytogenetic evaluation of the individual with developmental delay or mental retardation. Am College of Med Gen (ACMG) 2005;7:650-4.

25. Shevell MI, Bodensteiner JB. Cerebral palsy: defining the problem. Semin Pediatr Neurol 2004;11:2-10.

26. Medina MT, Amador CC, Hernandes R, Hesse H. Neurologic consequence of malnutrition. Semin Clin Neurol 2008;6:1-63. 